\title{
PEDAGOGICAL PSYCHOLOGY OF REPORT. ${ }^{1}$
}

\author{
OTTO LIPMANN, PH.D., \\ Berlin, Germany.
}

Ever since the earliest days of pedagogical psychology the problems of memory have occupied a prominent place in the consideration of investigators. But the treatment of these problems has been somewhat one-sided. Only that function of memory which expresses itself in learning and in retaining and forgetting material previously learned has been taken into account. The experiments, which are termed "memory"'-experiments simply, consist essentially in giving the observer some sort of material, usually verbal, with the instruction that he shall so master this material as to be able later verbally to reproduce it. 'Thus it is characteristic of this sort of experiment that from the beginning the attention is directed to that which is later to be reproduced.

Without doubt, these experiments do not exhaust the far more extended rôle which memory plays in our mental life. For we retain not only those impressions which were received when the attention was especially directed to them, but we re. member also experiences and details of experiences which were originally not direct objects of our attention. There can be no doubt that this latter function of memory is, not only for the adult, for whom it is the exception to "learn" in the narrow sense of the word, but also for the child, of uncommonly greater practical significance than that which comes into play in inemorizing.

It is the service of Stern (9) to have been the first to open up this other side of the memory-problem to an experimental treatment. He was especially interested in the legal signifirance of just this last-mentioned function of the memory, and

\footnotetext{
'Transiated from the author's manuscrint by DR. HeLeN D. Cook, Instructor in Psychology. Wellesley College. The word Aussagr is translated "report," except in the case of the Aursage of a Zrugon (legal witness), where the translation "testimony" is used.-Evirons.
} 
contrasted this process of reporting [Aussage-Leistung] with the phenomena connected with the process of learning. In truth, the testimony of a witness has to do, if not entirely, still very essentially, with those details of an experience to which, at the time, he did not especially direct his attention.

Accordingly, Stern formulates the question: What is the result whon some one who has had a certain experience is later called upon to give a report about the details of this experience. This problem, in many different phases, has been the subject of a large number of experimental investigations.' The material for the report has been varied (pictures, narratives, events, localities), as has been also the time intervening between the original experience [Wahrnehmung] and the report, the form of questioning and the division of attention during the experience. A comparison has been made also of reports of different categories of persons (educated-uneducated, masculine-feminine, adults-children). To this large number of formulations of the problem corresponds a large mass of detailed results, which, however, at the present time, can be considered only incompletely established. They are, in part, of a general psychological nature; in part they are directed toward solving the practical problem of the reliability of the testimony of witnesses. In this paper we shall confine ourselves to those results which seem of pedagogical signifirance; that it to say, to those which have to do with the reports of children.

The first aud most obvious result of the report-research is to show that reports are in general extremely unreliable. While this is true to a high degree even of the reports of adults, the number of misstatements shows a marked increase when the reports of clildren are investigated. And it must be noted in this connection that there was absolutely no reason why the observers should purposely tell an untruth. We may certainly assume that in all the experiments under consideration the report was always given "according to the best knowledge and belief" of the observer. When, in spite of this fact, so many mistakes are made, it must furnish food for thought not

\footnotetext{
$=(10),(4)$, and the bibliography in the Zeitschrift fir angeutandte Prychold. gic, rols. I and IV.
} 
only to the judge who has to do with the testimony of witnesses, but also to the educator. For how often the latter meets with notorious untruths, and is then all too ready with the accusation of "lying." Against such an attitude [ should like to emphasize what seems to me pedagogically the most important result of the report-research: that the deduction from untruthfulness to lying is by no means invariably justifiable; that, on the contrary, in addition to the will to speak the untruth, there are quite other causes for mistakes in reports; and that it is just in the case of the child that these other causes play an unusually important rôle.

When we attempt to classify the factors that can lead to $n$ false report we must distinguish between conditions which affect (1) the perceiving [Wahrnehmung], (2) the remembering and (3) the report itself.

Let us begin with the first, and ask what it is that differentiates the perception of the child from that of the adult in such a way as to result in a less reliable report. One might assume that the child's power to concentrate his attention on the reported object is actually less than that of the adult. For this assumption, howerer, we have no valid ground. On the other hand, I believe that we may rightly assume that the child and the adult direct their attention to entirely different details of an experience. For if a child is shown a picture and asked to describe what he sees-if, that is, a perception-report instead of a memory-report is demanded of him-it is astonishing how his interest and attention are directed toward details that, at first at any rate, the adult does not notice at all. And, on the other hand, the child does not notice, or at most notices only secondarily, just those details which seem to the adult the "essential"' ones. That this fact must play an important rôle in the memory-report as well, I have, though not strictly proved, still made very probable by the following argument (3) : If the distribution of attention were the same for all individuals, and only the degree of concentration showed quantitative differences, then those objects which were noticed most by one class of individuals, about which, that is, we obtain the best reports, would be the ones most noticed by other persons also. One would expect, of course, to find quantitative differ- 
ences in the absolute number of mistakes, but the order of objects when arranged according to the accuracy with which they were reported would be the same for all classes of observers. This is, however, not the case, and differences in such an order can, in my opinion, be due only to differences in the distribution of attention. It is true that no one has yet succeeded in determining how the child's distribution of attention differs from that of the adult. I can only mention, in this connection, a result of Stern's (8) which, while it presumably does not exhaust the differences with which we are here concerned, certainly has a beariug on the question. Stern distinguishes a "Substance"-stage, an "Actuality"-stage and a "Relation"- and "Quality"-stage. From the reports characteristic of these different stages we may perhaps conclude: that the child at first notices mainly objects; later he turns his attention to their properties and to actions, and only during the last stage does he notice the relations between objects. After noting these facts it will not seem strange to us that, in experiments as in life, the child's report seems more defective than that of the adult. For in the latter, as in the formèr, we ques. tion him mainly about those details which seem to us adults essential, but which are not at all "essential" to the child, and which he, therefore, leaves more or less unnoticed. We indeed have reasons for calling just those details essential, but for the child these reasons do not yet exist. If the child, in his turn, were to formulate the questions, probably the adult would suc. ceed equally ill in reporting details which for the child are essential. 'Thus far, then, we have strictly no right to call the report of the child faultier than that of the adult. Cautiously formulated, all that we ought to say is that the child reports certain things-and just those details that seem to the adult essential-more poorly than does the adult. Here, then, as almost everywhere in clild psychology, we find that we must trace quantitative differences-the number of mistakes in the report-back to qualitative-the distribution of attention. On every side we meet with the fact that the adult differs from the child not only in a bare more or less, but in a thus and so not capable of being quantified. 
This view seems, however, to leave one objection still unanswered, namely, if a child is questioned about things that he has not noticed, he might he expected to answer, "I don't know," and thus gaps in his report, but not actual mistakes would be explained. But both gaps and mistakes in a report evidently point to corresponding defects in the memory of the reported object, and here we find an intimate connection between gaps and mistakes. For we can observe in our own mental life a tendency to fill out somehow the gaps in our memories when once ouv attention is called to them; and, naturally, this filling out does not always occur in a way that correspond; to reality.

When, next, we ask how the child has his attention called to such memory-gaps, we come to a further group of factors that may result in mistakes in the report-those, namely, that lie in the condition of the report itself. An essential factor here is the form of the report, whether it is a free "narrative," or, on the other laand, an "interrogatory," consisting in answers to questions. As a matter of fact, the narrative is usually incomplete, but relatively free from mistakes, while in the interrogatory the answer "I don't know" seldom occurs, but ir large proportion of the statements are wrong. The reason is just that given above: by the question the child's attention is called to gaps in what he remembers, and these gaps he then fills out. If the question itself does not suggest an answer, then the filling out usually follows along customary lines. When, for example, I ask the color of a certain piece of furniture, I usually receive the answer "yellow" or "brown," even if the particular piece of furniture in question was of some other color. Other children (3), on the contrary-perhaps the less intelligent, though that is not yet determined-have a way of emancipating themselves from custom and giving free play to their fancy in filling out such gaps.

In this connection one question deserves more detailed treatment: Why does the child accept so readily for filling out the gaps in his memory any material that comes to hand, whether through suggestion, through his own imagination or through custom? This brings us to a further fundamental characteristic of the childisb imagination, which furnishes another rea- 
son why the child's reports are more faulty than those of the adult. This fundamental characteristic is that everything that is imagined is imagined as real. Independently of whether an image comes as a memory-image, or is called up by fancy or by suggestion, always at first it bears for the child the character of a memory-image, $i$. $t^{2}$., it plays the rôle of a real experience. In this crude formulation the statement holds, of course, only for the very small child. For soon the increasing store of experience brings with it the recognition that much which fancy pictures for its own pleasure behaves quite differently in crude reality.

"Leicht bei einander wolnen die Gedanken, Doch hart im Raume stossen sich die Sachen."

But even with the school child this recognition is relatively so little developed that the lack of it may be held responsible for many wrong reports.

A further discussion of the part played by fancy in causing. wrong reports may be omitted here, since, in the nature of the ease, this factor does not admit of an experimental treatment. But even here observation has brought to light much valuable material (7). On the other hand, the investigation of suggestibility (2) has proved to be a fruitful field for experimental report-research.

In discussing suggestion let us not confine ourselves to the narrower and technical sense of the term, but extend our study to include any influence of suggestive questions (6), though such influence is not by any means always that of suggestion proper. We find here a definite dependence of grade of suggestibility on the age of the observer; younger children prove to be very much more suggestible than older children or adults. In order to understand this fact we must make clear to ourselves the different possible ways in which suggestive questions may exert an influence. Let us consider, first, suggestion in the technical sense. This occurs when a question about a detail of an experience alters an actually existing lnowledge about that experience. For example, the observer lias seen a room with two windews, and remembers the fact correctly. Now, when asked if the room did not have three 
windows, he revises his memory and makes his report agree with the question. It is evident that such a result will be the more likely to appear the weaker and hazier the memor'y of this detail of the experience is, on the one hand, and, on the other, the more authority the questioner has over the person questioned. In the case of young children it is obvious that both these factors are present to a high degree. What ground we have for assuming that a child's memory of those details about which we usually ask is incomplete has been shown above. And the degree of authority which the questioner exerts over the one questioned may be assumed to be approximately proportional to the difference in their ages. Not only does the authority of the questioner under some circumstances cause the observer to revise his knowledge, but very often the effect of a question put by a person in authority is that the observer does not consult his own knowledge at all in giving his answer. The essence of the suggestive question, then, consists in the fact that it actually puts certain answers into the mouth of the person questioned. So that very often such an answer is given without any reflection, for the observer say's to himself, "If the respected person who is questioning me expects such an answer, then it must be the right one." Indeed, the authority of the questioner can, by means of suggestjve questions, bring about answers that are almost lies. The answer suggested by the question is sometimes given even contrary to the better knowledge of the observer, either because the latter is too shy to contradict, or because he wants to please the questioner or to escape from further questioning, etc.

After this discussion of what are presumaluly the most inlportant causes of the notorious inadequacy of children's reports we come to the educationally important question: whether and how the child's ability to report can be improved; whether, that is, a training in giving reports is possible, and by what means such a training would be carried out. This question, too, has repeatedly been investigated experimentally." It seems to me that the results of these researches show, in agreement with the theory stated above, that a training in

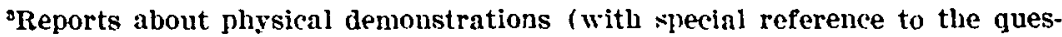
tion of training in reporting) in (1) and (5).
} 
siving reports is possible-but possible only when one can direct the child's attention to those details of an experience that seem to the adult the essential ones. In other words, the training in giving reports must imitate and accelerate the process that otherwise mere increasing years and the accompanying accumulation of daily experience brings about - the transformation of the child's distribution of attention to one corresponding to that of the adult. Several methods for accomplishing this training are conceivable. For one thing, one might use the report-experiment itself as a means of training." From the questions that are asked in this the child gradually learns what details he must notice. Such a training in reporting might easily be added as memory instruction to the usual instruction in observation. The only difference would lie in the fact that the objects would be described by the child not during preception, but after they had been shown to him and then taken away. Moreover, the instruction in observation itself may be used as a training in reporting, in that during the child's very perception of the object his attention may be called to the "essential" details and concentrated on just those details.

Further, a second very essential factor in a child's report can be influenced by memory-instruction. By calling the child's attention to his misstatements one teaches him to take a critical attitude toward his own report. In this way he learns-more quickly than he would learn through ordinary experience-that gaps in his memory may not be filled in at his own sweet will; that all material for the filling in that is furnished by fancy, custom or suggestion must first be tested as to its agreement with the actual experience reported ; finally, that if all the material that comes to mind for filling in the raps fails to stand the test of a thorough criticism, the answer "I don't know" is to be preferred to every doubtful answer.

For an experimental study, showing the nature of the improvement due to such training, see W. S. Foster. The Effect of Practice I pon Tisualizing and lipan the Reproduction of Visual Impressions. This Joural, Vol. II, No. 1. January, 1911, pp. 11-22.---Eoitors. 
REFEIENCES :

(1) BaAde, W. Die Wethodik der Tersuche und dic Inhalte der Text-Aussagen.

(2) Binet, A. La s'ugyestibilité. Volume III of the Bibliotheque de Pédagogie et de Psychologie. Paris: Srlhleicher Frères. 1900 .

(3) Inpansix, Otro. Mrethodologische Beitrüge zur Aussageforschung. Zeitschrift fur Angewandte Psychologie 2, 424-439. 1909.

(4) Lipanax, Oroo. Die Psychologie der Aussage (Sammelreferat). Philosophische Wochenschrift Bd. 2. 1900.

(5) Impanax, O'To. Die Schatzungen und die Ergebnisse der Farben-, Lolalisation-, und Sukscssionsfragen. Zeitsolurift für Angewandte I'sychologie, 4 (3/4) 189-332, 1910 (witl summary of the literature).

(6) LipMaxx, OTTo. Die Wirkung von Suggestivfragen. Zeit. sclurift fur Angewandte Psychologie, Bd. 1 u. 2. Auch Separat. Leipzig: J. A. Barth. 1908.

(i) S'lens, C. C. W. Erinnerung, Aussage und Luge in der crsten Kindheit. No. 2 der Monographien iber die sealische Entwicklung des Kindes. Leipzig: J. A. Barth, 1909.

(S) H'renN, W. Die Aussuge als geistige Leistung und als Terhörsprodukt. I. Teil. Beitrage /ur Psychologie der Aussage I (3), 1904.

(9) N'rens, W. Zur Psychologie der Alussage. Keitschrift für die gesanite Strafrechtswissens(haft, $2 \%(\% / 3), 1902$. Separat : Berliu, Gutentag.

(10) Sirers, IV. (Editor). Bciträge $\approx u$ Psychologic der Aussugc. Leijzig: J. A. Barth, I, 1903-1904 ; II, 190 5ั-1906. 